\title{
A BIBLIOTERAPIA COMO UM CAMPO DE ATUAÇÃO PARA O BIBLIOTECÁRIO: PERSPECTIVAS DOS DISCENTES DO CURSO DE BIBLIOTECONOMIA DA UFBA
}

\author{
BIBLIOTHERAPY AS A FIELD OF ACTION FOR THE LIBRARIAN: \\ PERSPECTIVES OF THE LIBRARIANS OF UFBA
}

\author{
Pamela Oliveira Assis ${ }^{I}$, Raquel do Rosário Santos ${ }^{I I}$, Ingrid Paixão de Jesus ${ }^{I I I}$ \\ Recebido em: 07-03-2019 \\ Aceito em:15-04-2019
}

\begin{abstract}
Resumo
A Biblioterapia é um dos possíveis campos de atuação do bibliotecário, porém há pouca abordagem a respeito desse assunto em sala de aula e o fato de as competências dos estudantes para assumirem esse campo não serem desenvolvidas a contento podem ser consideradas barreiras para a formação de futuros profissionais. Esses aspectos também motivaram a escolha desse tema de pesquisa. Assim, o objetivo deste estudo foi o de investigar quais as perspectivas dos discentes de Biblioteconomia sobre sua atuação no campo da Biblioterapia. Para isso, foram aplicados questionários com os discentes da Universidade Federal da Bahia, para saber suas opiniões a respeito do assunto. Além disso, procedeu-se a um mapeamento na literatura da Ciência da Informação para saber quais as competências que os bibliotecários devem dominar para atuar na Biblioterapia e que precisam ser desenvolvidas pelos discentes durante a graduação. Com essas etapas realizadas, foi possível observar que os discentes já ouviram falar sobre biblioterapia, mas a maioria não se sente preparada para atuar no campo por causa da falta de componentes curriculares específicos que os aproximem dessa temática. Conclui-se que, apesar de esses profissionais conhecerem um pouco sobre o tema, ainda é necessário que as matrizes curriculares se atualizem e abordem novos campos de sua atuação em sala.
\end{abstract}

Palavras-chave: Biblioterapia. Bibliotecário - perfil. Bibliotecário - competências. Campo de atuação - Biblioteconomia.

\begin{abstract}
Bibliotherapy is one of the possible fields of action of the librarian, but the lack of approach to this subject in the classroom and the fact that the students' competences to take on this field are not developed to the satisfaction can be considered barriers for the formation of future professionals. These aspects also motivated the choice of this research theme. Thus, the objective of this study was to investigate the perspectives of Librarianship students about their work in the field of Biblioterapia. For that, questionnaires were applied with the students of the Federal University of Bahia, to know their opinions on the subject. In addition, a mapping was carried out in the literature of Information Science to know what skills librarians must master in order to perform in Biblioterapia and that need to be developed by the students during graduation. With these steps accomplished, it was possible to observe that the students have already heard about bibliotherapy, but most do not feel prepared to work in the field because of the lack of specific curricular components that approach them in this theme. It is concluded that, although these professionals know a little about the subject, it is still necessary that curricular matrices are updated and address new fields of their performance in the classroom.
\end{abstract}

Keywords: Bibliotherapy. Librarian Profile. Librarian Skills. Field of Librarianship.

\footnotetext{
${ }^{\text {I }}$ Bacharel em Biblioteconomia e Documentação - e-mail: mell.oliveira20@ hotmail.com

IIDoutora em Ciência da Informação - Professora do Instituto de Ciência da Informação, da Universidade Federal da Bahia. - e-mail: quelrosario@gmail.com

III Mestranda em Ciência da Informação - UFBA - e-mail: ingridpaixao191@ gmail.com
} 


\section{INTRODUÇÃO}

Atualmente, devido às diversas mudanças e necessidades que surgem na sociedade políticas, econômicas, culturais, educacionais, tecnológicas, entre outras - as profissões se ressignificam e passam a ter novos campos de atuação, como vem ocorrendo com a Biblioteconomia. Um exemplo de um novo campo de atuação para os bibliotecários é a Biblioterapia, que, embora não seja recente, vem se apresentando como uma demanda e necessidade da sociedade.

A biblioterapia é entendida como um tratamento terapêutico em que se utiliza a leitura, em seu sentido amplo, para tratar diferentes problemas dos pacientes, desde os emocionais até os comportamentais. Também pode ser considerada como uma prática multidisciplinar, porquanto envolve bibliotecários, médicos, psicólogos, assistentes sociais, dentre outros profissionais. O objetivo dessa prática, entre outros, é o de promover a socialização entre pessoas e auxiliá-las a resolver seus problemas.

Os bibliotecários são profissionais que podem integrar a equipe multidisciplinar que desenvolve a biblioterapia, mas ainda existem indagações sobre essa atividade, especialmente sobre a aproximação e o interesse dos estudantes da área sobre esse fazer. Assim, questiona-se sobre o (des)conhecimento dos estudantes da área de Biblioteconomia a respeito das atividades da Biblioterapia. Nesse contexto, o que motivou a realização desta pesquisa foi a seguinte inquietação: os discentes de Biblioteconomia reconhecem e se sentem preparados, a partir do desenvolvimento de competências durante o curso, para atuar no campo da Biblioterapia? Para responder a essa questão, foi traçado o seguinte objetivo geral: analisar o perfil necessário, com base na literatura da Ciência da Informação, para favorecer a atuação dos discentes de Biblioteconomia no campo da Biblioterapia e a percepção desses sujeitos sobre a possibilidade de aplicar a biblioterapia.

Nesta pesquisa, de natureza descritiva, foram empregados dois métodos: o bibliográfico, por apresentar resultados de um levantamento de materiais já publicados em um nível de aprofundamento, e o estudo de caso, por analisar as percepções dos discentes do Curso de Biblioteconomia do Instituto de Ciência da Informação da Universidade Federal da Bahia (ICI/UFBA). Para a coleta dos dados, adotou-se o questionário, que foi analisado a partir de uma abordagem quantitativo-qualitativa.

Os resultados indicaram que os discentes já ouviram falar sobre a Biblioterapia, mas a maioria não se sente preparada para atuar nesse campo devido à falta de componentes curriculares específicos que os aproximem dessa temática. Portanto, apesar de os discentes conhecerem um pouco sobre o tema, ainda é necessário atualizar as matrizes curriculares e abordar novos campos de atuação desse profissional.

\section{BIBLIOTERAPIA: CONCEITOS E MÉTODO BIBLIOTERAPÊUTICO}

A palavra biblioterapia originou-se de dois radicais gregos: biblion, que significa livro, e therapeia, que significa terapia, tratamento etc. Portanto, biblioterapia é uma terapia realizada com livros. O termo 'biblioterapia' tem diversas definições, como a do Dorland's Ilustrated Medical Dictionary (1941 apud RATTON, 1975, p. 199), que a concebe como "[...] o emprego de livros e da sua leitura no tratamento de doenças mentais." Complementar a esse conceito, Mood e Limper (1973 apud CALDIN, 2001, p. 35), definem a biblioterapia como

[...] a utilização de materiais de leitura selecionados como coadjuvante terapêutico na Medicina e na Psiquiatria; a orientação na solução de problemas pessoais por meio da leitura dirigida; o tratamento do mal ajustado para promover sua recuperação à sociedade. 
Para Cohen (1994 apud SEITZ, 2006, p. 18), a biblioterapia "[...] é o uso da literatura com a orientação ou intervenção de um terapeuta." Rosa (2006, p. 16-19) reúne outros conceitos sobre a biblioterapia, conforme se pode observar no Quadro 1.

Quadro 1 - Conceitos de biblioterapia

\begin{tabular}{|l|l|}
\hline Autores & Conceitos \\
\hline Alice Bryan & $\begin{array}{l}\text { É a prescrição de materiais de leitura que auxiliem a desenvolver maturidade } \\
\text { e nutram e mantenham a saúde mental. }\end{array}$ \\
\hline L.H. Tweffort & $\begin{array}{l}\text { É um método subsidiário da psicoterapia; um auxílio no tratamento que, } \\
\text { através da leitura, busca a aquisição de um conhecimento melhor de si mesmo } \\
\text { e das reações dos outros, resultando em um melhor ajustamento à vida. }\end{array}$ \\
\hline Kenneth Appel & $\begin{array}{l}\text { É o uso de livros, artigos e panfletos como coadjuvantes no tratamento } \\
\text { psiquiátrico. }\end{array}$ \\
\hline Louise Rosenblatt & $\begin{array}{l}\text { É uma ajuda para o ajustamento social e pessoal; a literatura imaginativa é } \\
\text { útil para ajustar o indivíduo tanto em relação aos seus conflitos íntimos como } \\
\text { em conflitos com outros. Como o pensamento e o sentimento estão } \\
\text { interligados, o processo de pensamento reflexivo estimulado pela leitura é um } \\
\text { prelúdio para a ação. }\end{array}$ \\
\hline Orsini & $\begin{array}{l}\text { É uma técnica que pode ser utilizada para fins de diagnóstico, tratamento e } \\
\text { prevenção de moléstias e de problemas pessoais. }\end{array}$ \\
\hline Mattews e Lonsdale & $\begin{array}{l}\text { Constitui-se em uma terapia de leitura imaginativa, que compreende a } \\
\text { identificação com uma personagem, a projeção, a introspecção e a catarse. } \\
\text { Caldin }\end{array}$ \\
\hline $\begin{array}{l}\text { É a leitura dirigida e discussão em grupo, que favorece a interação entre as } \\
\text { pessoas, levando-as a expressarem seus sentimentos: os receios, as angústias } \\
\text { e os anseios. }\end{array}$ \\
\hline
\end{tabular}

Fonte: Adaptado de Rosa (2006, p. 16-19)

Apesar das diferentes conceituações, é possível perceber que elas estão sempre direcionadas para o lado emocional e o medicinal. A biblioterapia tem uma base técnica, apoiada em princípios e em métodos definidos, mas vai além quando envolve o sujeito e sua singularidade, buscando tratar da estruturação individual e de sua relação com o social. Assim, defende-se que a biblioterapia é uma prática fundamentada em técnicas, métodos e princípios multidisciplinares que auxiliam os sujeitos de maneira intra e interpessoal.

A biblioterapia utiliza diferentes instrumentos. Porém seu foco são os livros, a fim de ajudar pessoas a encontrarem soluções para seus problemas físicos e emocionais. Por meio dos livros, as pessoas podem se informar, despertar o prazer para a leitura, a curiosidade e o autoconhecimento e se integrar à sociedade. Apesar de a biblioterapia usar com mais frequência os livros, como dispositivo terapêutico, é possível encontrar na literatura projetos em que se utilizaram imagens, músicas e filmes para motivar, reabilitar e socializar indivíduos que estavam passando por dificuldades em sua vida pessoal.

Biblioterapia pode ser tanto um processo de desenvolvimento pessoal como um processo clínico de cura, que utiliza literatura selecionada, filmes, e participantes que desenvolvem um processo de escrita criativa com discussões guiadas por um facilitador treinado com o propósito de promover a integração de sentimentos e pensamentos a fim de promover autoafirmação, 
autoconhecimento ou reabilitação. (MARCINKO 1989 apud FERREIRA, 2003, p. 38)

Para que a biblioterapia alcance resultados efetivos, é necessário identificar o perfil e os problemas apresentados pelos sujeitos que necessitam de suas atividades. A partir dessa interação e do diagnóstico, o profissional que irá adotar a biblioterapia em seu campo de trabalho reconhecerá as ações e as atividades que poderão ser trabalhadas com o grupo e/ou o sujeito. Assim, o exercício da biblioterapia deve ser planejado sistematicamente e desenvolvido de maneira consciente, pois, ao realizar essas atividades, o profissional assume uma responsabilidade com a vida emocional dos sujeitos.

A literatura cita três tipos de biblioterapia: a institucional, a clínica e a de desenvolvimento pessoal. Marcinko (1989 apud FERREIRA, 2003, p. 38) e Pereira (1996, p. 57-58) conceituam esses tipos de biblioterapia da seguinte maneira:

a) biblioterapia institucional: é a terapia em que se utiliza a literatura didática e pode ser aplicada em grupo ou individual por uma instituição, com auxílio de uma equipe multidisciplinar, que pode ser composta de bibliotecários, educadores, médicos, assistentes sociais, entre outros profissionais. Tem como objetivo informar, ajudar no desenvolvimento pessoal e na tomada de decisões etc.;

b) biblioterapia clínica: utiliza a literatura imaginativa para trabalhar com problemas comportamentais sociais, emocionais, morais etc. Seu objetivo é de contribuir para que esses pacientes mudem ou melhorem seu comportamento e suas atitudes, através da participação voluntária, ou não, dessa terapia. Esse tipo de biblioterapia é aplicado em hospitais, institutos e comunidades, por bibliotecários, médicos, terapeutas ocupacionais, psicoterapeutas, entre outros profissionais;

c) biblioterapia desenvolvimental: nesse tipo de biblioterapia, usa-se a literatura imaginativa e didática para assistir pessoas que procuram por ajuda voluntariamente e tem o objetivo de auxiliar em tarefas comuns, lidar com problemas do cotidiano, como divórcio, gravidez, morte etc. Pode ser aplicada em instituições educacionais por bibliotecários, educadores, assistentes sociais, entre outros profissionais.

A Biblioterapia não se limita a uma área de atuação, já que envolve práxis, técnicas e métodos multidisciplinares, que contam com a participação não só do bibliotecário, mas também de outros profissionais, como psicólogos, assistentes sociais, médicos, entre outros. Ao envolver uma equipe multidisciplinar no exercício da biblioterapia, cada profissional poderá contribuir de maneiras distintas, de acordo com suas competências e seus conhecimentos, para que o planejamento do programa terapêutico seja elaborado de modo que atenda às necessidades de cada paciente e obtenha resultados favoráveis.

Apesar de a biblioterapia poder ser aplicada pelo bibliotecário, ainda se questiona o papel desse profissional nesse trabalho.

Desde 1914, a Biblioterapia é considerada um ramo da Biblioteconomia, mas, até hoje, ainda há discussão sobre sua aplicação por bibliotecários. Alguns autores afirmam que cabe ao bibliotecário apenas a seleção do material; outros concordam que os bibliotecários estão preparados para aplicar a Biblioterapia, sendo necessário apenas um treinamento especial. (SEITZ, 2006, p. 31) 
Entende-se que, para o bibliotecário atuar na biblioterapia, é preciso desenvolver competências para interagir e se comunicar com os sujeitos, ter empatia e sentimento acolhedor e compreendê-los. Miranda (2004, p. 115) define a competência como um "[...] conjunto de conhecimentos, habilidades e atitudes correlacionados que afeta parte considerável da atividade de alguém e se relaciona com o desempenho. Pode ser medida segundo padrões preestabelecidos."

As competências podem e devem ser desenvolvidas durante a graduação. $\mathrm{O}$ discente que deseja trabalhar em determinado campo de atuação deve, ao longo do curso, preparar-se para desenvolver o perfil indicado e demandado pela sociedade e pelo mercado de trabalho. Assim, durante a formação, ele deve buscar desenvolver competências e produzir novos conhecimentos, com vistas a alcançar o perfil traçado pela instituição à qual está vinculado e, especialmente, perceber e atingir as expectativas e as demandas sociais.

Para Almeida Júnior (2002, p. 137), perfil "[...] é o norteador da estrutura formal para sua formação. É com base nesse perfil que se ergue, constrói e se desenvolve o processo pedagógico com vistas a preparar adequadamente um profissional para assumir as funções exigidas pela profissão." Na diretriz curricular do Curso de Biblioteconomia, assim como em projetos pedagógicos, pode-se encontrar o perfil que se espera dos bibliotecários. Nesses documentos, encontram-se as diversas competências citadas anteriormente e que são reconhecidas como necessárias aos bibliotecários.

A partir dessa discussão sobre as competências para desenvolver a biblioterapia, é necessário levantar a questão sobre a divulgação desse campo de atuação nos Cursos de Biblioteconomia. Silva e Pinheiro, desde 2008, já apresentavam críticas sobre a falta de cursos que disponibilizavam disciplinas que preparassem o estudante para atuar nesse campo.

É notória a existência de um número reduzido de Cursos de Biblioteconomia que oferecem formação adequada às competências exigidas para o bibliotecário desenvolver práticas biblioterapêuticas. Em geral, o foco dos Cursos de Biblioteconomia reside em serviços, sistemas de informação e tecnologias, o que de certa forma, direciona os profissionais da área, apenas às questões técnicas de processamento, armazenamento e disseminação da informação, negligenciando, assim, o comprometimento desses profissionais com a responsabilidade social da profissão que abraçaram. (SILVA; PINHEIRO, 2008, p. 2).

Assim, as matrizes dos Cursos de Biblioteconomia devem apresentar opções que possibilitem ao discente capacitar-se e traçar um caminho ao longo da graduação que não só esteja ligado a questões técnicas da área, mas também direcionem os estudantes a se apropriarem de outros campos de atuação que existem na área, como, por exemplo, a Biblioterapia. Ter um bibliotecário competente para atuar em campos ligados à questão social é tão importante quanto um que possa gerir com eficiência uma biblioteca. Assim, é relevante pensar sobre qual é o profissional que as escolas de Biblioteconomia estão formando; quais as competências, a postura e os papéis que esses profissionais precisam desenvolver, o que refletirá sobre seu entendimento e reconhecimento na sociedade.

Quanto à atuação do bibliotecário na biblioterapia, é possível perceber, com base nas ações já citadas, que existe espaço e que esse profissional deve atuar com competência no campo da Biblioterapia, para além das ações que se referem à organização e à seleção de materiais informacionais. "O biblioterapeuta é, primeiramente, um bibliotecário que vai mais adiante no campo da orientação da leitura e torna-se um profissional especializado" (KINNEY 1962 apud PEREIRA 1996, p. 69). Com especialização e desenvolvimento das competências necessárias para trabalhar com a biblioterapia, o bibliotecário pode contribuir para que os sujeitos com diversos problemas possam melhorar e descobrir o quão gratificante pode ser 
trabalhar com essa técnica. Nesse sentido, justifica-se a realização de pesquisas como esta, que investiguem as perspectivas dos discentes de Biblioteconomia sobre a atuação no campo da Biblioterapia, bem como as competências relacionadas a essa atuação.

\section{PROCEDIMENTOS METODOLÓGICOS}

Como citado na introdução, o problema investigado nesta pesquisa foi se os discentes de Biblioteconomia reconhecem e se sentem preparados, a partir do desenvolvimento de competências durante o curso, para atuarem no campo da biblioterapia. Para responder a essa questão, desenvolveu-se o seguinte objetivo geral: analisar o perfil necessário, com base na literatura da Ciência da Informação, para favorecer a atuação do discente de Biblioteconomia no campo da Biblioterapia e a percepção desses sujeitos sobre a possibilidade de realizarem práticas de biblioterapia.

Para atender ao objetivo geral, foram traçados os seguintes objetivos específicos: mapear competências necessárias para os profissionais de Biblioteconomia atuarem na biblioterapia, por meio da literatura da Ciência da Informação, a fim de traçar um perfil a ser desenvolvido pelo estudante dessa área que deseja atuar no campo; investigar o que os discentes de Biblioteconomia entendem sobre biblioterapia; investigar se os discentes de Biblioteconomia se sentem preparados para atuar no campo da Biblioterapia.

Este estudo caracteriza-se como uma pesquisa descritiva que, de acordo com Gil (2010, p. 27), "[...] têm como objetivo a descrição das características de determinada população." Quanto aos procedimentos, classifica-se em dois tipos: bibliográfica e de estudo de caso, posto que foi desenvolvida uma pesquisa em materiais já publicados em fontes informacionais, como livros e periódicos, e possibilitou aprofundar as percepções dos discentes do Curso de Biblioteconomia do Instituto de Ciência da Informação da Universidade Federal da Bahia (ICI/UFBA) e identificar sua visão sobre a biblioterapia e a possível atuação nesse novo campo. É importante ressaltar que foi adotado o critério de intencionalidade, ao selecionar para a amostra turmas específicas do referido curso, prováveis concluintes e os que estavam em processo de conclusão, ou seja, os que estavam no penúltimo semestre do ano de 2018, quando foi realizada esta pesquisa. Essa escolha foi feita por se tratar de discentes que já conhecem o currículo do curso, já têm um amadurecimento acerca da área e suas possibilidades de atuação e estão prestes a integrar o mercado de trabalho.

Para coletar os dados, adotou-se a técnica de aplicação de questionário, que, segundo Lakatos e Marconi (2010, p. 184), "é um instrumento de coleta de dados, constituído por uma série ordenada de perguntas, que devem ser respondidas por escrito e sem a presença do entrevistador." Para esta pesquisa, foi elaborado um questionário por meio do formulário eletrônico do Google Drive, composto de oito questões - seis fechadas e duas abertas - com o objetivo de, primeiramente, identificar informações básicas a respeito dos discentes para que fosse possível construir um perfil dos respondentes e, em seguida, investigar qual o nível de conhecimento desse respondente acerca do tema e se ele se sente preparado para atuar na área.

A abordagem qualitativa foi adotada Para a análise e a interpretação das respostas dos discentes, foi adotada a abordagem qualitativa, e para as respostas que puderam ser quantificadas, a quantitativa.

\section{APRESENTAÇÃO E DISCUSSÃO DOS RESULTADOS}

A apresentação e a discussão dos resultados estão alinhadas ao objetivo da pesquisa - o de analisar o perfil necessário, com base na literatura da Ciência da Informação, para favorecer a atuação do discente de Biblioteconomia no campo da Biblioterapia e a percepção desses sujeitos sobre a possibilidade de realizarem essas práticas. Por isso, os resultados obtidos na etapa de coleta dos dados são apresentados a partir do levantamento bibliográfico de textos que tratam sobre biblioterapia, mais especificamente, que apresentam as competências necessárias 
para os profissionais fazerem atividades nesse campo. Também são apresentados e discutidos os resultados obtidos com a aplicação do questionário aos discentes do Curso de Biblioteconomia da UFBA.

\subsection{PERFIL APRESENTADO PARA O ESTUDANTE DE BIBLIOTECONOMIA QUE} DESEJA ATUAR NO CAMPO DA BIBLIOTERAPIA: O QUE DIZ A LITERATURA?

Como resultado da pesquisa bibliográfica, foi possível perceber que o campo exige do profissional um perfil bem específico. De acordo com Kinney (1962 apud PEREIRA, 1996, p. 67), especialista em Biblioteconomia Institucional, as competências necessárias para desenvolver ações de biblioterapia são:
a) estabilidade emocional;
b) bem-estar físico;
c) caráter;
d) personalidade para trabalhar com pessoas.

Além dessas competências, para o bibliotecário que deseja aplicar a biblioterapia, especificamente no campo da Psiquiatria, Cubillos (2008) indica mais algumas e os conhecimentos necessários para isso:

a) competências pessoais: comunicação interpessoal com diversos tipos de usuário; capacidade de aprender continuamente; estabilidade pessoal; interesse real em trabalhar com outros; capacidade de trabalhar em equipe; empatia com os outros; sensibilidade, paciência e espírito dinâmico;

b) conhecimentos: informação atualizada sobre as tendências dominantes, pautas de conduta, diretrizes e serviços; terminologia própria da área de saúde; informações especializadas, sob o ponto de vista legal, técnico e teórico e sua disponibilidade.

O discente deve desenvolver e aprimorar essas competências ainda na graduação, pois é durante esse período que vai ser possível desenvolver o perfil profissional esperado e exigido pela sociedade. E como a matriz curricular do Curso de Biblioteconomia dificilmente oferece o que é necessário para que todos os discentes saiam competentes nos diversos campos existentes, eles devem saber qual o campo com o qual tem mais afinidade, além do que a universidade lhe possibilitou, e se qualificar bem mais.

Além de dominar as competências já citadas, para que essa técnica alcance o resultado esperado, os profissionais precisam estar preparados emocionalmente para tratar dos indivíduos, porquanto não podem internalizar os problemas das pessoas, razão por que é necessária uma maturidade emocional. Nessa perspectiva, devem ser empáticos e compreensivos com as pessoas e com o que as aflige, sem levar isso para sua vida pessoal. Deve, ainda, estimular a comunicação com o indivíduo que está sendo tratado, utilizar diversos meios para conquistar sua confiança e fazer com que haja uma reação ao que foi trabalhado durante a terapia, de maneira que o sujeito exponha o que sente e o que sofreu, a fim de que isso seja superado. A criatividade também é importante como característica interessante para os bibliotecários, que precisam saber trabalhar em grupo, afinal, como já foi dito, a biblioterapia é uma técnica multidisciplinar.

Na literatura, é possível encontrar relatos sobre a aplicação da biblioterapia e entender a importância de desenvolver essas competências. Caldin (2002) analisou, em seu artigo, um projeto de biblioterapia para crianças internadas no Hospital Universitário de Santa Catarina, em que foram utilizadas atividades como leitura, dramatização, contação de histórias, músicas, dentre outras que possibilitaram aos profissionais trabalharem com diversas competências ao 
mesmo tempo, como criatividade, dinamismo e comunicação. A união dessas competências para o desenvolvimento do projeto resultou no interesse das crianças pelo acervo infantil do hospital e lhes concedeu um momento mágico em que o riso predominava sobre qualquer dor que elas estivessem sentindo.

Em João Pessoa - na Paraíba - Pereira (1996) desenvolveu um trabalho de aplicação da biblioterapia no Instituto dos Cegos da Paraíba Adalgisa Cunha, com pessoas que se tornaram deficientes visuais. Os resultados apresentados nesse projeto indicaram como competências necessárias: sentimento acolhedor, empatia, paciência, sensibilidade, capacidade de aprendizagem contínua e comunicação.

Quanto à aplicação da biblioterapia, Rubin (1978) lista uma série de diretrizes básicas para que os bibliotecários possam elaborar o programa biblioterapêutico. Essas diretrizes expressam a necessidade de algumas habilidades que o bibliotecário precisa desenvolver ao elaborar o programa. Como exemplo, pode-se citar o fato de que, para realizar reuniões, ele precisa saber trabalhar em grupo e identificar e mediar a solução de problemas. O autor acrescenta que, para conduzir a terapia, ele deve ter passado por um treinamento adequado e estar capacitado para conduzir as discussões e formar grupos homogêneos para leitura e debates de temas previamente escolhidos e com materiais, técnicas e metodologias adequadas para as ações terapêuticas.

Em síntese, é essencial que o bibliotecário, ao aplicar a biblioterapia, planeje e realize os procedimentos apresentados pelo autor. E para que esses procedimentos sejam exitosos, o bibliotecário deve ter conhecimento de gestão, a fim de adotar técnicas, métodos e materiais que auxiliem a efetivar ações biblioterapêuticas. Além do perfil traçado pela literatura, o discente deve ter um olhar sensível para a prática da biblioterapia.

\subsection{ENTENDIMENTO DOS DISCENTES DE BIBLIOTECONOMIA SOBRE A BIBLIOTERAPIA}

Ao investigar sobre se os discentes conhecem a biblioterapia, constatou-se que os 20 respondentes já têm algum tipo de conhecimento sobre esse campo. Esse resultado deve ser ressaltado, porque não existe uma disciplina na matriz curricular do curso que trate sobre a biblioterapia. A partir desse dado, existem duas hipóteses: a primeira sobre o compartilhamento de um conteúdo oculto, que o docente aborda durante as disciplinas, ainda que não esteja formalmente apresentado no programa ou na matriz curricular; a segunda hipótese é a de que os discentes buscam outros conhecimentos fora da sala de aula, por exemplo, em palestras, nos estágios, em grupos de pesquisa, entre outros.

A partir da análise da primeira hipótese, ratifica-se a necessidade de atualizar as matrizes curriculares dos cursos e de dar ao discente a oportunidade de conhecer os diversos campos em que sua profissão permeia. Lucas, Caldin e Silva (2006) referiram, em um trecho do seu artigo, que assumir novos campos e contribuir para fortalecer a profissão é essencial. Os discentes de Biblioteconomia não só precisam, como também têm total competência para assumir não só o campo da Biblioterapia, como também vários outros que a Biblioteconomia, como uma área interdisciplinar, possibilita ocupar.

Quanto aos meios de acesso à informação sobre a biblioterapia que os respondentes poderiam indicar - eles podiam assinalar mais de uma questão - do total de 20 respondentes, $11(31 \%)$ conheceram a biblioterapia por meio de colegas; nove (26\%), na sala de aula, e sete (20\%), em eventos da área. Apesar de poucos discentes indicarem a sala de aula como ambiente de acesso à informação sobre a biblioterapia, esse também foi um ambiente que tratou em algum momento sobre o tema. Esse resultado indica, novamente, que é preciso formalizar o conteúdo no programa de disciplinas que se aproximem dessa temática ou desenvolver um componente curricular que trate sobre a biblioterapia. Pode-se pressupor, a partir desse resultado, que, se existissem cursos, projetos de pesquisa ou disciplinas que abordassem o tema durante a 
graduação, eles teriam uma boa recepção por parte dos discentes, já que, apesar de a Biblioterapia não fazer parte da matriz curricular do curso, $31 \%$ dos respondentes afirmaram que conheceram o assunto em conversas com colegas. Isso significa que eles demonstram interesse pelo assunto.

Ainda sobre esses resultados, a opção "fontes impressas e eletrônicas" corresponde ao campo "outros" no questionário, em que os discentes apontaram livros, internet e artigos científicos, como outros meios em que tiveram acesso às informações sobre a biblioterapia.

A pesquisa também procurou saber quais as ações da biblioterapia que os discentes conhecem. Nesse quesito, eles poderiam indicar mais de uma ação. Assim, a contação de histórias foi indicada por 18 (24\%) dos respondentes, e a encenação com fantoches, por 16 (21\%). Apesar de não ser uma ação tão comum, 13 (17\%) dos respondentes marcaram também atividades relacionadas a músicas, que podem ser observadas nos estudos de Silva (2014) e Caldin (2002). Ações como essas devem ser aprendidas e desenvolvidas pelos discentes durante sua formação, pois, além da possibilidade de apoiarem no tratamento terapêutico, podem ser realizadas para auxiliar no desenvolvimento cognitivo e no processo de aprendizagem, por exemplo, em bibliotecas públicas e escolares.

Referente a esses resultados, um respondente indicou o simples ato de ler como uma ação biblioterapêutica. Esse dado foi apresentado como "outros" pelo respondente. Assim, percebe-se que os respondentes conhecem as possibilidades de ações em que podem desenvolver a biblioterapia. Apesar de os 20 participantes da pesquisa terem afirmado que já ouviram falar sobre a biblioterapia, o estudo indicou que apenas seis (30\%) deles tiveram alguma experiência ligada à prática. Esse número ainda é pouco significativo, quando comparado com o número dos que conhecem a biblioterapia e suas ações. A partir desse resultado, pode-se inferir que os discentes carecem de ambientes - seja na Academia, seja nos estágios e/ou nos cursos - que propiciem a prática de ações ligadas à biblioterapia.

Por reconhecer a relevância da biblioterapia nos tratamentos com diversos sujeitos, em distintos contextos, tomando como base os pressupostos teóricos de Silva e Pinheiro (2008), entende-se que os Cursos de Biblioteconomia, especialmente o da UFBA, devem contribuir para que os discentes possam conhecer as ações biblioterapêuticas e os métodos e as técnicas ligados a essas ações e, em sua formação, exercitar sob a supervisão de especialistas que o orientarão nesse processo, a fim de que realizem essas ações com mais segurança e responsabilidade.

Também foi investigada a percepção dos discentes quanto ao reconhecimento da possibilidade de adotar a leitura como uma ação terapêutica. Sobre isso, o Respondente A afirmou:

Sim, pois a leitura além de estimular a criatividade, poderá servir de refúgio para os problemas cotidianos, abrindo os horizontes e proporcionando novas sensações. A leitura nos transporta para outros universos.

Outra resposta que vale ser destacada foi elaborada pelo Respondente L:

Por proporcionar ao 'paciente' um alicerce para lidar com um determinado problema dando-lhe através da leitura um ponto de fuga e apresentando-o um universo com novos contextos que podem ampliar sua visão.

Tanto a primeira quanto a segunda respostas demonstram uma percepção clara e conhecimento de que a leitura é muito importante como ação terapêutica. Quando o primeiro respondente afirma que a leitura, além de estimular a criatividade serve de refúgio, ele faz uma distinção clara e expõe seu conhecimento de que a leitura pode e deve ser uma prática realizada com diversos objetivos, tanto para o desenvolvimento cultural, o cognitivo e o terapêutico, entre 
outros. Assim, tanto o bibliotecário quanto o estudante de Biblioteconomia devem ter a percepção, o conhecimento e as práticas para desenvolverem a leitura nos diversos propósitos e ambientes em que necessidade.

\subsection{PERCEPÇÃO DOS DISCENTES DE BIBLIOTECONOMIA SOBRE SUA FORMAÇÃO PARA ATUAREM NO CAMPO DA BIBLIOTERAPIA}

Também foi investigado se o discente considera necessária a existência de uma disciplina de Biblioterapia na matriz curricular do Curso de Biblioteconomia. Dezenove respondentes afirmaram positivamente, e um preferiu se abster e não respondeu à questão.

Entre as respostas positivas, vale destacar as seguintes:

Sim. Precisamos ampliar a formação dos estudantes da área e suas possibilidades de atuação profissional e social. Acredito que uma disciplina optativa voltada para esta temática seria de grande proveito. (Respondente B).

Acho sim. Penso que seja essencial, uma vez que a formação profissional do bibliotecário necessita atender aos anseios da sociedade atual no sentido informacional, cultural, educacional e de lazer. (Respondente C).

Sim. Uma profissão que se diz social, precisa capacitar os futuros profissionais para uma atuação mais humana. (Respondente J).

Percebe-se que todas as respostas apresentam uma percepção da Biblioteconomia enquanto uma área social e por isso que deve buscar atender as necessidades da sociedade. Para os respondentes, a biblioterapia não só é uma ação terapêutica como também social, que deve ser apresentada e desenvolvida desde a universidade, durante sua formação acadêmica.

Quanto à percepção dos discentes sobre se sentirem preparados para desenvolver as ações de biblioterapia, a partir de suas experiências na universidade, no curso, nos estágios e por meio de suas leituras, três deles responderam positivamente, e 17 afirmaram que não se sentem preparados para isso, conforme se pode observar nas respostas abaixo:

Não me sinto preparada para desenvolver ações de biblioterapia. Não somos preparados para isso. Podemos fazer sim, mas através de esforços próprios, através da literatura existente sobre o tema. (Respondente D).

Não me sinto preparado porque a universidade não me deu base para desenvolver um projeto. Poderia desenvolver atividades lúdicas ligadas a livros a partir de outras vivências, mas é muito diferente de um projeto biblioterapêutico. (Respondente $\mathrm{E})$.

Não. Apesar da minha ampla gama de leitura e da minha necessidade voraz de ler, não me sinto preparado, pois não saberia identificar o problema do outro e o que seria uma leitura que o auxilie a superá-lo. (Respondente L).

Os três respondentes disseram que a universidade precisa fortalecer ações que os auxiliem a praticar atividades biblioterapêuticas e que apenas a teoria e o acesso à literatura não são suficientes para a realização de tais atividades. Por essa razão, o curso deve disponibilizar uma disciplina - obrigatória ou optativa - que trate sobre esse tema e promova práticas que auxiliem os estudantes a desenvolverem essas ações, com vistas a prepará-los para atuarem de maneira efetiva e consciente e seguros de suas responsabilidades sociais. 


\section{CONSIDERAÇÕES FINAIS}

Os resultados encontrados nesta pesquisa indicaram que os atuais e os futuros profissionais que se interessam em atuar no campo da Biblioterapia se qualificam e se aproximam desse campo de maneira autônoma, pois, em alguns casos, a Academia só apoia de maneira indireta, durante o processo de formação na graduação. Também foi constatado que a literatura sobre a Biblioteconomia e a Ciência da Informação ainda é incipiente. Nesse sentido, é preciso ampliar estudos e pesquisas que tenham o objetivo de abordar questões relativas à atuação do bibliotecário no campo da Biblioterapia e perceber que esses sujeitos podem realizar, a fim de favorecer o processo de mediação e apropriação da informação, ampliando as investigações sobre o acesso à leitura como um bem público que é direito de todos.

Por meio da literatura, é possível traçar um perfil para o profissional que deseja atuar nesse campo do conhecimento e as competências necessárias para isso, tais como: sensibilidade, criatividade, empatia, comunicação interpessoal, capacidade de trabalhar em grupo, entre outras. Como se pode observar, grande parte das competências são voltadas para que o indivíduo se sinta bem e à vontade com aquele profissional. É muito importante que o "paciente" e o profissional que atua no desenvolvimento da Biblioterapia mantenham uma boa relação, para que os resultados sejam positivos. Nessa perspectiva, a Biblioterapia deve ser tratada em sala de aula, e os discentes precisam aperfeiçoar essas competências, para exercer com segurança as ações ligadas a esse campo do saber.

Ressalte-se, todavia, que, apesar de a literatura oferecer um embasamento teórico, também é necessária a prática da biblioterapia, para que os estudantes possam exercitar esse fazer e se apropriarem desse campo. Embora a pesquisa tenha apontado que todos os respondentes ouviram falar sobre a Biblioterapia, o fato de não haver uma disciplina ou curso em que esse tema seja abordado com mais profundidade pode ser o motivo de os discentes não se sentirem preparados para atuarem nesse campo.

Assim, considerando o exposto, compreende-se que é necessário atualizar as matrizes curriculares que integram a Biblioterapia, seja como componente curricular específico ou como tema tratado em algum componente. $\mathrm{O}$ ambiente acadêmico é que abre as portas para o leque de campos de atuação da Biblioteconomia, e se essa opção não é dada ao discente durante o curso, o bibliotecário poderá ter dificuldade de assumir seu lugar em uma equipe multidisciplinar para aplicar a Biblioterapia, por exemplo.

Nesse contexto, entende-se que, em outras pesquisas, devem-se investigar as ementas do Curso de Biblioteconomia, a fim de saber quais são os cursos, na esfera nacional, que oferecem disciplinas que abordem sobre a biblioterapia, pois a percepção dos discentes e a literatura mostraram que se trata de um campo sobremaneira relevante, não só para os atuais e os futuros bibliotecários, como também para toda a sociedade.

\section{REFERÊNCIAS}

ALMEIDA JÚNIOR, Oswaldo Francisco. Formação, formatação: profissionais da informação produzidos em série. In: VALENTIM, Marta Lígia Pomim (Org.). Formação do Profissional da Informação. São Paulo: Polis, 2002. p. 133-148.

CALDIN, Clarice Fortkamp. Biblioterapia: um cuidado com o ser. São Paulo: Porto das ideias, 2010. 
CALDIN, Clarice Fortkamp. Biblioterapia para crianças internadas no hospital universitário da ufsc: uma experiência. Encontros Bibli: Revista eletrônica de Biblioteconomia e Ciência da Informação, Florianópolis, n. 14, p. 38-54, 2002. Disponível em: https://periodicos. ufsc.br/index.php/eb/article/view/1518-2924.2002v7n14p38. Acesso em: 9 jul. 2018.

CALDIN, Clarice Fortkamp. A leitura como função terapêutica: biblioterapia. Encontros Bibli: Revista Eletrônica de Biblioteconomia e Ciência da Informação, Florianópolis, v. 6, n. 12, p. 32-44, 2001. Disponível em: http://www.brapci.inf.br/_repositorio/2010/07/pdf_ 8190236306_0011510.pdf. Acesso em: 10 dez. 2018.

CATARSE. In: MICHAELIS - Dicionário Brasileiro da Língua Portuguesa. São Paulo: Melhoramentos, 2017. Disponível em: http://michaelis.uol.com.br/busca?id=aqYj. Acesso em: 10 jul. 2018.

CUBILLOS, Mariela Ferrada. Usuarios de bibliotecas con discapacidad psiquiátrica. Serie Bibliotecología y Gestión de Información, Santiago, n. 39, p. 4-24, ago. 2008. Disponível em: https://core.ac.uk/download/pdf/11884589.pdf. Acesso em: 11 dez. 2018.

FERREIRA, Danielle Thiago. Biblioterapia: uma prática para o desenvolvimento pessoal. ETD: Educação Temática Digital, Campinas, v. 4, n. 2, p. 35-47, jun. 2003. Disponível em: https://periodicos.sbu.unicamp.br/ojs/index.php/ etd/article/view/620/635. Acesso em: 9 out. 2018.

GIL, Antonio Carlos. Como Elaborar Projetos de Pesquisa. 5. ed. São Paulo: Atlas, 2010.

LAKATOS, Eva Maria; MARCONI, Marina de Andrade. Fundamentos de Metodologia Científica. 7. ed. São Paulo: Atlas, 2010.

LUCAS, Eliane R. de Oliveira; CALDIN, Clarice Fortkamp; SILVA, Patrícia V. Pinheiro da. Biblioterapia para crianças em idade pré-escolar: estudo de caso. Perspectivas em Ciência da Informação, Belo Horizonte, v. 11, n. 3, p. 398-415, set./dez. 2006. Disponível em: http://www.scielo.br/scielo.php?script=sci_ issuetoc\&pid=1413-993620110003\&lng=pt\&nrm=iso. Acesso em: 14 dez. 2018.

MIRANDA, Silvânia Vieira. Identificando competências informacionais. Ciência da Informação, Brasília, DF, v. 33, n. 2, p. 112-122, maio/ago. 2004. Disponível em: http://www.scielo.br/pdf/ci/v33n2/a12v33n2.pdf. Acesso em: 9 ago. 2018.

PEREIRA, Marília Mesquita Guedes. Biblioterapia: proposta de um programa de leitura para portadores de deficiência visual em bibliotecas públicas. João Pessoa: UFPB, 1996.

RATTON, Angela Maria Lima. Biblioterapia. Revista da Escola de Biblioteconomia da UFMG, Belo Horizonte, v. 4, n. 2, p. 198-214, set. 1975. Disponível em: http://portaldeperiodicos.eci.ufmg.br/reb/. Acesso em: 8 dez. 2018.

ROSA, Aparecida Luciene Resende. As Cartas de Ana Cristina César: uma contribuição para a Biblioterapia. 2006. 84 f. Dissertação (Mestrado em Letras) - Uniiversidade do Vale do Rio Verde (UninCor), Três Corações, 2006. Disponível em: http://www.unincor.br/images/ imagens/2017/mestrado_letras/APARECIDA_LUCIENE_RESENDE_ROSA.pdf. Acesso em: 19 dez. 2018. 
RUBIN, Rhea Joyce. Using Bibliotherapy: a guide to theory and pratice. London: Oryx, 1978.

SEITZ, Eva Maria. Biblioterapia: uma experiência com pacientes internados em clínica médica. Florianópolis: Habitus, 2006.

SILVA, Ana Mafalda Carvalho. Biblioterapia Aplicada Em Contexto de Saúde mental: um estudo de caso. 2014. 215 f. Dissertação (Mestrado em Ciências Documentais) - ECATI Departamento de Ciências da Comunicação, Universidade Lusófona de Humanidades e Tecnologias, Lisboa, 2014. Disponível em:

http://recil.grupolusofona.pt/jspui/handle/10437/5059. Acesso em: 5 nov. 2018.

SILVA, Wilton Pereira da; PINHEIRO, Edna Gomes. A face oculta da biblioterapia na biblioteca universitária: os ditos e os não ditos dos bibliotecários da Biblioteca Central da UFPB. In: SEMINÁRIO NACIONAL DE BIBLIOTECAS UNIVERSITÁRIAS, 15., 2008, São Paulo. Anais eletrônicos[...]. São Paulo: Cruesp, 2008. Disponível em: http://www.sbu.unicamp.br/snbu2008/anais/site/pdfs/3497.pdf. Acesso em: 29 jan. 2019.

\section{AGRADECIMENTOS}

O presente trabalho foi realizado com apoio da Coordenação de Aperfeiçoamento de Pessoal de Nível Superior - Brasil (CAPES) - Código de Financiamento 001. 